\title{
Optimization for the Simultaneous Determination of Zinc in Environmental Samples With Calcon by Adsorptive Stripping Voltammetry : Response Surface Methodology
}

\author{
DESWATI ${ }^{1 *}$, HAMZAR SUYANI ${ }^{1}$, \\ IZZATI RAHMI ${ }^{2}$ and HILFI PARDI ${ }^{1}$ \\ ${ }^{1}$ Department of Chemistry, Faculty of Mathematics and Natural Science, Andalas. \\ University, Kampus Limau Manis, Padang 25163, Indonesia. \\ ${ }^{2}$ Department of Mathematics, Faculty of Mathematics and Natural Science, Andalas \\ University, Padang 25163, Indonesia. \\ *Corresponding author E-mail : deswati_ua@yahoo.co.id \\ http://dx.doi.org/10.13005/ojc/330455
}

(Received: June 02, 2017; Accepted: June 29, 2017)

\begin{abstract}
A procedure for the optimization simultaneous determination zinc by adsorptive stripping voltammetry has been done. The purpose of this study was to obtain the optimum condition of zinc simultaneously. To achieve these objectives, required an optimization technique by using response surface methodology (RSM), with central composite design (CCD). The research design was used CCD with 4 variables, 3 level and 31 a combination of treatments. The first step of $2^{k}$ factorial design optimization is: to give the highest level of code values $(+1)$, the lowest level $(-1)$ and code $(0)$ as the center point. Programs have been used for statistical data processing, namely Minitab using RSM. Based on data analysis, the obtained optimum conditions for the simultaneous determination of zinc is the calcon concentration of $0.7018 \mathrm{mmol} / \mathrm{L} ; \mathrm{pH}=7.1845$; accumulation potential $-0.5628 \mathrm{~V}$, and the accumulation time $62.16 \mathrm{~s}$. The optimum conditions obtained relative standard deviation (RSD) $2.5 \%$, recovery of $98.01 \%$, linier range $(0.2-105) \mu \mathrm{g} / \mathrm{L}$, and limit of detection (LOD) $1.21(\mu \mathrm{g} / \mathrm{L})$. This RSM has been successfully applied to the simultaneous determination of zinc in environmental samples.
\end{abstract}

Keywords: Simultaneous determination, adsorptive stripping voltammetry, trace zinc, response surface methodology, environmental samples

\section{INTRODUCTION}

Heavy metal contamination in the environment is a major concern worldwide because of toxicity of these metals and their potential threat to human health. Currently, quantification of heavy metals relies upon the collection of liquid discrete for subsequent laboratory analysis using techniques 
such as ICP-MS, AAS, GC, HPLC, FT-IR, and GS/ $M S^{1}$, but these instruments too expensive and are not practically applied especially in Indonesia. Therefore, the analysis is often limited to laboratory level. Since such requirements are greatly met with electrochemical methods.

Electrochemical methods are widely used in the field of analytical chemistry is sensitive, selective, simple, less costly and less time consuming ${ }^{2}$, simplicity, fast response, and suitability for the preparation of inexpensive and portable instrumentations ${ }^{3}$. Therefore we need a sensitive and selective method for determining the levels of trace amounts of metal ions, namely the adsorptive stripping voltammetry (AdSV). Adsorptive stripping voltammetry is chosen as an alternative method because it has many advantages including: high salt content from seawater not disturbing in analysis, high sensitivity, low detection limit on $\mu \mathrm{g} / \mathrm{L}$ scale $(\mathrm{ppb})$, easy use and easy sample preparation, rapid analysis, inexpensive infrastructure ${ }^{4-12}$. In addition, by this method, it is possible to study the chemical specimens of heavy metals ${ }^{13}$, which can not be done by other methods. The toxicity of heavy metals is determined from its chemical species ${ }^{14-15}$. Almost all methods of determining metals in very small quantities require considerable time at the pre-concentration stage before measurement. In voltammetric stripping adsorptive pre-concentration phase time is shorter, generally less than 1 minute $^{7-8,12,16}$.

The previous research, to find the optimum condition, determination of metal ions $\mathrm{Cd}, \mathrm{Cu}, \mathrm{Pb}$ and $\mathrm{Zn}^{17}$ and $\mathrm{Fe}, \mathrm{Co}, \mathrm{Ni}$ and $\mathrm{Cr}^{18}$ in either singular or simultaneous form of AdSV, is done by observing the effect of one of the variables being changed while the other variable is kept at a constant level. This optimization technique is called the optimization of one variable or one factor at that time.

The weakness of the optimization of one factor is that optimization does not take into account the interaction effects between the variables studied. Therefore, this technique does not describe the full effect of parameters on the response ${ }^{19-22}$. Another disadvantage of one-factor optimization is an increase in the number of experiments required to conduct research, leading to increased time and increased consumption of reagents and materials. To overcome this problem, an analytic procedure optimization technique is needed by using RSM.

AdSV is a highly sensitive and selective technique ${ }^{7-8,21-22}$, the response obtained in the form of peak current (Ip) is strongly influenced by the following variables, namely, the calcon concentration, $\mathrm{pH}$, potential accumulation and time accumulation. Therefore, it is important to determine the optimization of these parameters, which will affect the measurement of peak currents in order to improve the quality of the analysis results ${ }^{23}$. However, in order to reach such a high sensitivity, the experiment must be carefully designed and important experimental factors, which can affect both response and accuracy, need to be optimized. A well-designed experiment can provide signals with superior quality compared to those measured without optimization ${ }^{24-25}$.

The purpose of this research is to get the optimum condition of $\mathrm{Zn}$ metal ion, so it can be applied to the analysis of the metal in environmental samples (seawater, fresh water, tap water, vegetables, and fruits) simultaneously. To achieve that goal, an analytical procedure optimization technique is required using RSM with $C C D^{19-29}$. The analytic parameters of the $\mathrm{Zn}$ metal ions are determined as follows: detection limits, linear range, correlation coefficient, recovery and relative standard deviation (RSD).

\section{EXPERIMENTAL DETAILS}

\section{Material and Instruments}

To the vessel voltammeter, $10 \mathrm{~mL}$ of mixed standard solutions of $\mathrm{Cd}(\mathrm{II}), \mathrm{Cu}(\mathrm{II}), \mathrm{Pb}$ (II) and $\mathrm{Zn}$ (II) $10 \mu \mathrm{g} / \mathrm{L}$ were added $0.2 \mathrm{~mL} \mathrm{KCl} 0.1 \mathrm{M}$ and $0.2 \mathrm{~mL}$ $20 \mathrm{~mL}$ of solution.

The Instrument used in this research is Metrohm 797 Computrace with HMDE working electrode, reference electrode of $\mathrm{Ag} / \mathrm{AgCl} / \mathrm{KCl}$, and Pt electrode as supporting electrode; $\mathrm{pH}$ meters Griffin model 80, Griffin \& George Loughborough, England; and analytical balance of Mettler AE 200, Toledo OH-USA; As well as glass equipment commonly used in laboratories. 


\section{General Procedure}

The research design used in this study, as a tool for optimization are CCD with 4 variables, 3 levels/level, and 31 treatment combinations. The first step of $2^{k}$ factorial design optimization is code, where the highest level $(+1)$, the lowest level $(-1)$ and code (0) as a center point. The program for statistical data processing is Minitab by using RSM (Table 1).

Calcon concentration, $\mathrm{pH}$, potential accumulation and time accumulation adjusted according to experimental design of CCD in Table 2 , below. From Table 2, we get the response of the peak currents of metal ions $\mathrm{Cd}, \mathrm{Cu}, \mathrm{Pb}$ and $\mathrm{Zn}$ simultaneously.

\section{Determination of Sampling Site and Sample Preparation}

The sampling method is done by purposive sampling, which is done by taking into account the condition of the research area also the current and the depth of the research area. This is intended to see to what extent the concentration of pollutants spread. To know the content of heavy metals in sea water is done sampling in sea water taken around Bungus, water tap from research laboratory of Chemistry Department, lake water from Maninjau Lake and river water taken from Lubuk Minturun. Samples of water prior to analysis were preserved with $65 \% \mathrm{HNO}_{3}$ with a ratio of $2: 1000$ and filtered using Whatman 42 filter paper ${ }^{30}$.

Vegetable samples used in this study are, cauliflower, mustard greens, eggplant, and broccoli,

Table 1: CCD variable level for independent parameters of the metal ion mixture (Cd, $\mathrm{Cu}, \mathrm{Pb}$ and $\mathrm{Zn}$ )

\begin{tabular}{lllll}
\hline Factors & \multicolumn{3}{c}{ Levels } & \multicolumn{2}{c}{$\mathbf{C d}, \mathbf{C u}, \mathbf{P b}, \mathbf{Z n})$} \\
& & $\mathbf{- 1}$ & $\mathbf{0}$ & $\mathbf{+ 1}$ \\
\hline $\begin{array}{l}\text { Calcon concentration } \\
\text { (mM) }\end{array}$ & $\mathrm{C}$ & $\mathbf{0 . 6}$ & $\mathbf{0 . 7}$ & 0.8 \\
$\mathrm{pH}$ & $\mathrm{pH}$ & 5 & 6 & 7 \\
$\begin{array}{l}\text { Potential accumulation } \\
\text { (V) }\end{array}$ & $\mathrm{E}$ & -0.7 & -0.6 & -0.5 \\
$\begin{array}{l}\text { Time accumulation } \\
(\mathrm{s})\end{array}$ & $\mathrm{T}$ & 40 & 60 & 80 \\
\hline
\end{tabular}

Source : level 0 from previous research ${ }^{4}$ while the fruits used include apples, banana kepok, melon and dragon fruit. Samples of vegetables and fruits before the determination of $\mathrm{Zn}$ metal content is determined first the water content, then do wet destruction with the addition of nitric acid pa and perchloric acid pa.

Each sample of $0.5000 \mathrm{~g}$ was carefully weighed and mashed, put into a Kestergum digestion flask. Further, the wet was destructed by the addition of $5 \mathrm{ml}$ of concentrated nitric acid and 0.5 $\mathrm{ml}$ of concentrated perchloric acid, shaken and left overnight. Next, heated to the digestor block starting at $100^{\circ} \mathrm{C}$, after the yellow vapor is exhausted the temperature is increased to $200^{\circ} \mathrm{C}$. The destruction is terminated when the white vapor and liquid in the flask remain about $0.5 \mathrm{~mL}$, cooled and diluted with doubly destilled water and the volume is adjusted to $50 \mathrm{~mL}$, shaken until homogeneous and left overnight and disarrayed ${ }^{32}$.

Clear solution is ready to be determined by $\mathrm{Zn}$ metal content with Voltammeter and Atomic Absorption Spectrophotometer as a comparison. The determination of the optimum conditions used in this study is the procedure developed by the previous research team ${ }^{4,7-9,11-12, ~ 17-18 . ~}$

\section{Detection Method}

The procedure of determining RSD (relative standard deviation), LOD (limit of detection), LR (linear range) and recovery has been done by previous researchers The procedure of determining RSD (relative standard deviation), LOD (limit of detection), LR (linear range) and recovery has been done by previous researchers ${ }^{4,7-9,11-12, ~ 17-18 . ~}$

\section{RESULT AND DISCUSSIONS}

\section{Optimization of Zinc Using One Variable}

The optimization by observing the effect of one variable in the determination of trace metal $\mathrm{Zn}$ in the presence of calcon has been done ${ }^{1}$. The optimum condition as follow: calcon concentration $0.7 \mathrm{mM}, \mathrm{pH} 7$, potential accumulation $-0.6 \mathrm{~V}$, time accumulation $70 \mathrm{~s}$. At the optimum conditions, the relative standard deviation was obtained with 8 replicates $(n=8)$ measurements standard solution $\mathrm{Zn}(\mathrm{II}) 10 \mathrm{u} \mathrm{g} / \mathrm{L}$ was $0.86 \%$, respectively. This technique does not describe the full effect 
on the response parameters and optimization of these factors is the increase in the number of trials required to do research, which leads to increased time and increased consumption of reagents and materials. Therefore to overcome this problem, an optimization technique of analytical procedures is by using RSM.

\section{Optimization of Zinc Using RSM}

The polynomial equations, the effects of calcon concentration $\left(\mathrm{x}_{1}\right), \mathrm{pH}\left(\mathrm{x}_{2}\right)$, potential accumulation $\left(\mathrm{x}_{3}\right)$, and time accumulation $\left(\mathrm{x}_{4}\right)$ on peak current $(w)$, were obtained using the statistical software package, Minitap release 16. For an experimental design with four factors, the model includes linier, quadratic, cross terms and can expressed by equation (1) :

$y=\beta o+\beta_{1} x_{1}+\beta_{2} x_{2}+\beta_{3} x_{3}+\beta_{4} x_{4}+\beta_{11} x_{1}^{2}+\beta_{22} x_{2}^{2}+$ $\beta_{33} x_{3}^{2}+\beta_{44} x_{4}^{2}+\beta_{12} x_{1} x_{2}+\beta_{13} x_{1} x_{3}+\beta_{14} x_{1} x_{4}+\beta_{23} x_{2} x_{3}+$ $\beta_{24} x_{2} x_{4}+\beta_{34} x_{3} x_{4}$

Table 2: Experimental design of RSM for optimization simultaneous determination of $\mathrm{Cd}, \mathrm{Cu}, \mathrm{Pb}$ and $\mathrm{Zn}$ with Calcon

\begin{tabular}{|c|c|c|c|c|c|c|c|c|}
\hline \multirow[t]{2}{*}{ Run } & \multirow[b]{2}{*}{$\begin{array}{l}\text { Calcon } \\
(\mathrm{mM})\end{array}$} & \multirow[b]{2}{*}{$\mathrm{pH}$} & \multirow{2}{*}{$\begin{array}{l}\text { Factor } \\
\text { Potential } \\
\text { (V) }\end{array}$} & \multirow[b]{2}{*}{ Time(s) } & \multirow[b]{2}{*}{ Cd } & \multicolumn{2}{|c|}{ Peak current (nA) } & \multirow[b]{2}{*}{$\mathrm{Zn}$} \\
\hline & & & & & & $\mathrm{Cu}$ & $\mathrm{Pb}$ & \\
\hline 1 & 0.6 & 5 & -0.7 & 40 & 21.75 & 129.74 & 52.22 & 57.58 \\
\hline 2 & 0.6 & 5 & -0.5 & 40 & 12.17 & 174.41 & 54.45 & 57.16 \\
\hline 3 & 0.6 & 5 & -0.7 & 80 & 37.35 & 178.61 & 105.90 & 43.44 \\
\hline 4 & 0.6 & 5 & -0.5 & 80 & 11.61 & 176.06 & 104.21 & 49.35 \\
\hline 5 & 0.6 & 7 & -0.7 & 40 & 16.36 & 266.66 & 40.21 & 87.60 \\
\hline 6 & 0.6 & 7 & -0.5 & 40 & 9.56 & 284.95 & 44.71 & 92.37 \\
\hline 7 & 0.6 & 7 & -0.7 & 80 & 23.61 & 269.02 & 38.17 & 77.73 \\
\hline 8 & 0.6 & 7 & -0.5 & 80 & 9.45 & 251.44 & 75.64 & 84.67 \\
\hline 9 & 0.8 & 5 & -0.7 & 40 & 25.11 & 180.35 & 41.40 & 61.13 \\
\hline 10 & 0.8 & 5 & -0.5 & 40 & 13.12 & 182.27 & 38.77 & 54.13 \\
\hline 11 & 0.8 & 5 & -0.7 & 80 & 48.71 & 191.26 & 79.17 & 54.13 \\
\hline 12 & 0.8 & 5 & -0.5 & 80 & 10.05 & 176.11 & 57.54 & 46.14 \\
\hline 13 & 0.8 & 7 & -0.7 & 40 & 92.35 & 295.00 & 39.16 & 83.35 \\
\hline 14 & 0.8 & 7 & -0.5 & 40 & 62.63 & 293.86 & 37.28 & 92.71 \\
\hline 15 & 0.8 & 7 & -0.7 & 80 & 101.69 & 313.50 & 40.20 & 90.03 \\
\hline 16 & 0.8 & 7 & -0.5 & 80 & 70.97 & 276.99 & 39.19 & 105.80 \\
\hline 17 & 0.7 & 6 & -0.6 & 60 & 104.33 & 221.07 & 80.86 & 101.49 \\
\hline 18 & 0.7 & 6 & -0.6 & 60 & 100.35 & 231.13 & 81.85 & 104.32 \\
\hline 19 & 0.7 & 6 & -0.6 & 60 & 105.21 & 232.14 & 80.86 & 105.29 \\
\hline 20 & 0.7 & 6 & -0.6 & 60 & 104.12 & 223.12 & 79.36 & 103.41 \\
\hline 21 & 0.7 & 6 & -0.6 & 60 & 103.13 & 222.07 & 83.14 & 103.43 \\
\hline 22 & 0.7 & 6 & -0.6 & 60 & 102.23 & 221.32 & 81.26 & 102.21 \\
\hline 23 & 0.7 & 6 & -0.6 & 60 & 104.12 & 222.04 & 81.26 & 101.21 \\
\hline 24 & 0.532 & 6 & -0.6 & 60 & 15.61 & 204.06 & 86.38 & 98.24 \\
\hline 25 & 0.7 & 4.32 & -0.6 & 60 & 19,67 & 201.89 & 74.87 & 92.89 \\
\hline 26 & 0.7 & 6 & -0.768 & 60 & 28.48 & 169.23 & 69.04 & 84.43 \\
\hline 27 & 0.7 & 6 & -0.6 & 26,4 & 12.25 & 123.32 & 33.70 & 88.11 \\
\hline 28 & 0.868 & 6 & -0.6 & 60 & 39.90 & 118.98 & 45.76 & 84.98 \\
\hline 29 & 0.7 & 7.68 & -0.6 & 60 & 78.77 & 117.77 & 69.87 & 97.65 \\
\hline 30 & 0.7 & 6 & -0.432 & 60 & 7.35 & 226.99 & 46.84 & 99.76 \\
\hline 31 & 0.7 & 6 & -0.6 & 93,6 & 12.72 & 186.71 & 87.97 & 83.61 \\
\hline
\end{tabular}


Where $y$ in the AdSV predicted response, $x_{1}, x_{2}, x_{3}$, and $x_{4}$ are the independent variables, $\beta$ o is intercept (constant), $\beta_{\mathrm{i}}$ is the linier coefficient, $\beta_{\mathrm{ii}}$ is the squared coefficient and $\beta_{\mathrm{ij}}$ is the cross coefficient. The explained variation percentage was expressed by the the determination coefficient $R^{2}$ at $5 \%$ statistical significance level.

The data was processed, which resulting the regression coefficient in the second orde model Table 3.

Table 3: Regression coefficients in the second order model

\begin{tabular}{ll}
\hline Term & Coefficient \\
\hline Constanta & 105.833 \\
$\mathrm{x}_{1}$ & 0.244 \\
$\mathrm{x}_{2}$ & 14.274 \\
$\mathrm{x}_{3}$ & 2.912 \\
$\mathrm{x}_{4}$ & -2.412 \\
$\mathrm{x}_{1}{ }^{*} \mathrm{x}_{1}$ & -7.966 \\
$\mathrm{x}_{2}{ }^{*} \mathrm{x}_{2}$ & -6.672 \\
$\mathrm{x}_{3}{ }^{*} \mathrm{x}_{3}$ & -7.795 \\
$\mathrm{x}_{4}{ }^{*} \mathrm{x}_{4}$ & -9.998 \\
$\mathrm{x}_{1}{ }^{*} \mathrm{x}_{2}$ & 1.966 \\
$\mathrm{x}_{1}{ }^{*} \mathrm{x}_{3}$ & 0.180 \\
$\mathrm{x}_{1}{ }^{*} \mathrm{x}_{4}$ & 2.148 \\
$\mathrm{x}_{2}{ }^{*} \mathrm{x}_{3}$ & 2.275 \\
$\mathrm{x}_{2}{ }^{*} \mathrm{x}_{4}$ & 3.068 \\
$\mathrm{x}_{3}{ }^{*} \mathrm{x}_{4}$ & 1.491 \\
\hline
\end{tabular}

$y=105.833+0.244 x_{1}+14.2744$ $x_{2}+2.912 x_{3}-2.412 x_{4}-7.966 x_{1}^{2}-6.672 x_{2}^{2}-7.795 x_{3}^{2}-9$. $998 x_{4}^{2}+1.966 x_{1} x_{2}+0.180 x_{1} x_{3}+2.148 x_{1} x_{4}+2.275 x_{2} x_{3}$ $+3.068 \mathrm{x}_{2} \mathrm{x}_{4}+1.491 \mathrm{x}_{3} \mathrm{x}_{4}$

Based on Table 4, test procedures are performed on the second order model. This hypothesis test is used to test the significance of the regression model, ie to test whether there are free variables (including quadratic and interaction effects) have a significant effect on the response variable.

The hypotheses tested were:

$\mathrm{HO}: \beta \mathrm{i}=0$,

$\mathrm{H} 1$ : there is $\beta \mathrm{i} \neq 0 ; \mathrm{I}=1,2,3, \ldots, \mathrm{k}$

Based on Table 2, the regression parameter test simultaneously yields p-value of 0.001 , meaning that the $p$-value obtained is smaller than the significance level used by $\alpha=0.05$. Thus it is decided to reject $\mathrm{Ho}$ and it is concluded that there are independent variables that have a significant effect on the response variable, so that the second order model can be accepted.

It can be seen (Table 4) the test results for each type of influence independent variable to the response variables include linear, quadratic and interaction effects. The $p$-value for linear and quadratic effects are 0.001 (smaller than the $\alpha$ level used at 0.05). The effects of these effects (linear and quadratic) have a significant influence

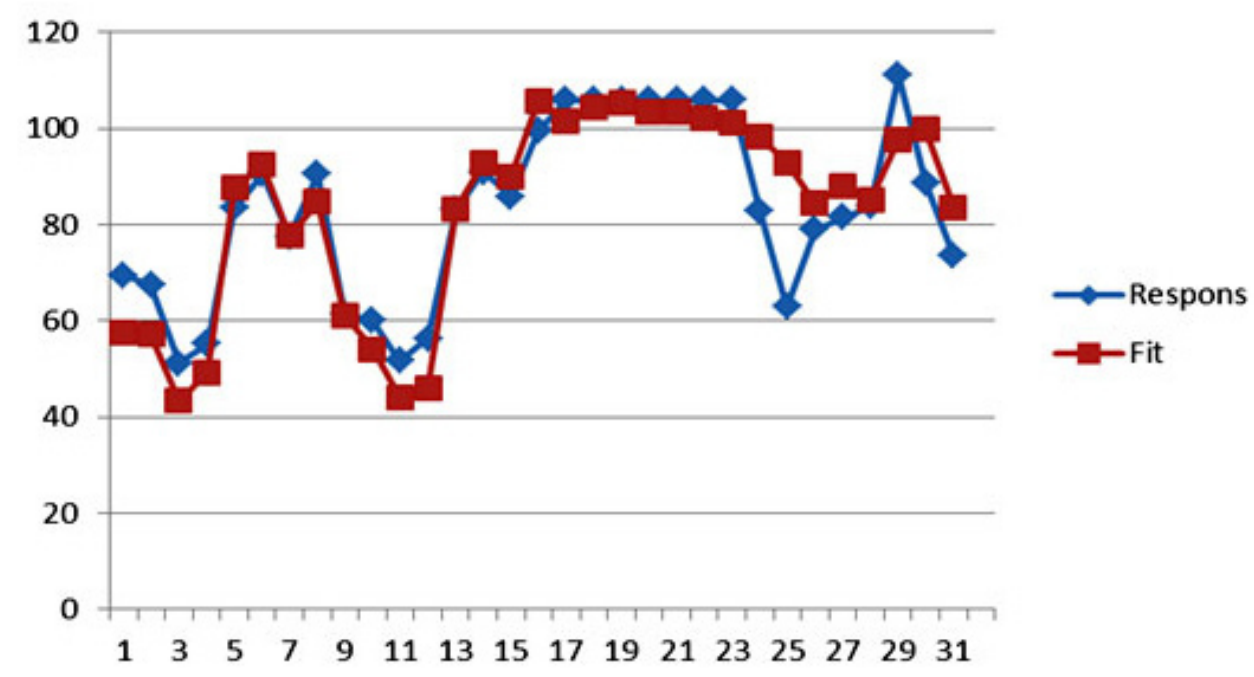

Fig. 1: Plot between the response value and expected value 
on the response variables. In other words, there is at least one linear influential variable and at least one quadratic variable influences the response variable. While for interaction effect test obtained $p$-value value of 0.825 , which means statistically, none of the interaction effects that have a significant effect on the response.

Furthermore, the indicator of the accuracy of the model, based on the coefficient of determination $\left(R^{2}\right)$ obtained a value of $81.60 \%$., Meaning the percentage of the diversity of responses capable of being explained by the second order model is $81.60 \%$. Thus the second order model already has a fairly high level of accuracy. It can also be seen from the plot between the response value (experimental results) with the expected value of response (from the second order model) as can be seen in Figure 1.

From Figure 1, it can be seen that most of the alleged values obtained from the second order model are very close to the true response value. Thus the second order model gives a high accuracy of estimation.

\section{Determination of Stasioner Point}

Based on the value of regression coefficient in Table 3 we can compile matrices b and B as follows:

Table 4: ANOVA second orde model

\begin{tabular}{|c|c|c|c|c|c|c|}
\hline Sumber & DF & Seq SS & Adj SS & Adj MS & $\mathbf{F}$ & $\mathbf{P}$ \\
\hline Regressi & 14 & 10343.5 & 10343.5 & 738.82 & 5.07 & 0.001 \\
\hline Liniar & 4 & 4723.7 & 4723.7 & 1180.92 & 8.10 & 0.001 \\
\hline$x_{1}$ & 1 & 1.3 & 1.3 & 1.29 & 0.01 & 0.926 \\
\hline$x_{2}$ & 1 & 4412.7 & 4412.7 & 4412.70 & 30.27 & 0.000 \\
\hline$x_{3}^{2}$ & 1 & 183.6 & 183.6 & 183.63 & 1.26 & 0.278 \\
\hline$x_{4}^{3}$ & 1 & 126.0 & 126.0 & 126.05 & 0.86 & 0.366 \\
\hline Square & 4 & 5214.7 & 5214.7 & 1303.68 & 8.94 & 0.001 \\
\hline$x_{1}^{*} x_{1}$ & 1 & 1436.2 & 1063.2 & 1063.21 & 7.29 & 0.016 \\
\hline$x_{2}{ }^{*} x_{2}$ & 1 & 957.7 & 745.9 & 745.92 & 5.12 & 0.038 \\
\hline$x_{3}{ }^{*} x_{3}$ & 1 & 1145.9 & 1017.9 & 1017.94 & 6.98 & 0.01 \\
\hline$x_{4}^{*} x_{4}$ & 1 & 1675.0 & 1675.0 & 1674.95 & 11.49 & 0.004 \\
\hline Interaction & 6 & 405.1 & 405.1 & 67.52 & 0.46 & 0.825 \\
\hline$x_{1}^{*} x_{2}$ & 1 & 61.9 & 61.9 & 61.86 & 0.42 & 0.524 \\
\hline$x_{1}{ }^{*} x_{3}^{2}$ & 1 & 0.5 & 0.5 & 0.52 & 0.00 & 0.953 \\
\hline$x_{1}{ }^{*} x_{4}$ & 1 & 73.8 & 73.8 & 73.79 & 0.51 & 0.487 \\
\hline$x_{2}{ }^{*} x_{3}$ & 1 & 82.8 & 82.8 & 82.81 & 0.57 & 0.462 \\
\hline$x_{2}^{2}{ }^{*} x_{4}^{3}$ & 1 & 150.6 & 150.6 & 150.55 & 1.03 & 0.325 \\
\hline$x_{3}^{2 *} x_{4}^{4}$ & 1 & 35.6 & 35.6 & 35.58 & 0.24 & 0.628 \\
\hline Residu Error & 16 & 2332.5 & 2332.5 & 145.78 & & \\
\hline Lack-of-Fit & 10 & 2319.1 & 2319.1 & 231.91 & 103.61 & 0.000 \\
\hline Pure Error & 6 & 13.4 & 13.4 & 2.24 & & \\
\hline Total & 30 & 12676.0 & & & & \\
\hline
\end{tabular}

Table 5: Result of optimum condition of Zn with RSM

\begin{tabular}{lll}
\hline Variable & Optimal value (with encoding) & Optimal value (without encoding) \\
\hline $\mathrm{x}_{1}$ & 0,18026 & 0,7018 \\
$\mathrm{x}_{2}$ & 1,18448 & 7,1845 \\
$\mathrm{x}_{3}$ & 0,37207 & $-0,5628$ \\
$\mathrm{x}_{4}$ & 0,10816 & 62,1632 \\
\hline
\end{tabular}


a. Plot contour and surface response on condition $x_{3}$ and $x_{4}$ at stationary point

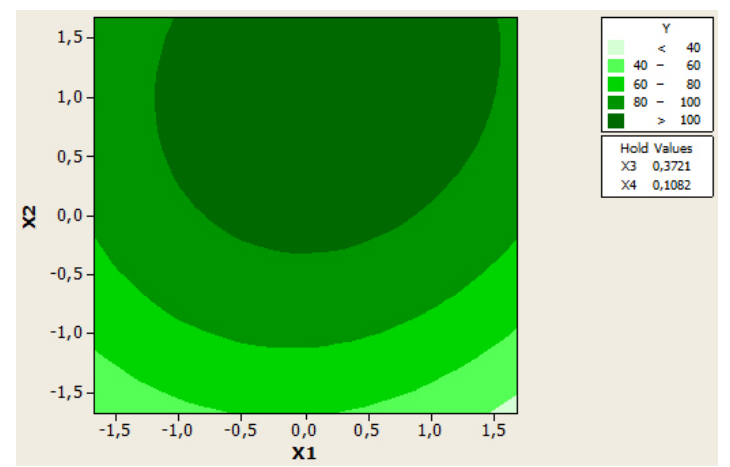

Contour plot of Peak current (Zn) against $x_{1}$ and $x_{2}$

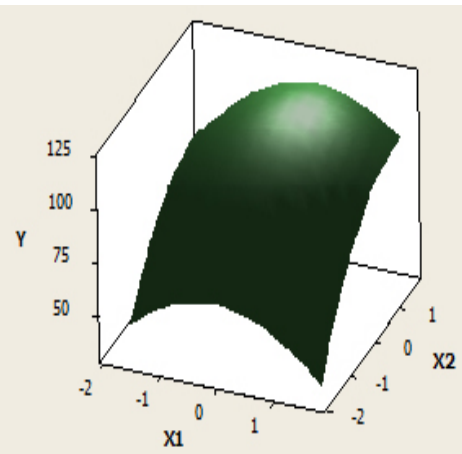

Surface plot of peak current (Zn) against $x_{1}$ and $x_{2}$

b. Plot contour and surface response on condition $x_{2}$ and $x_{4}$ at stationary point

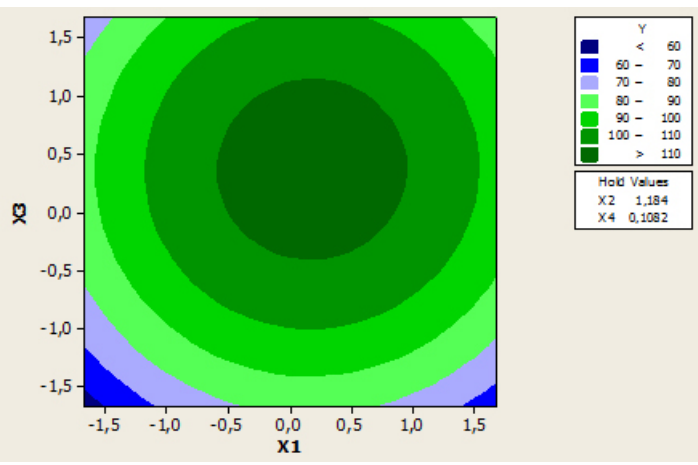

Contour plot of peak curret $(\mathrm{Zn})$ against $x_{1}$ and $x_{3}$

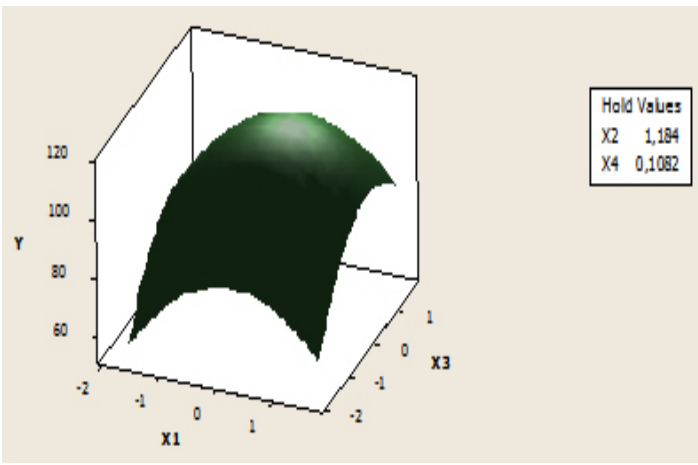

Surface plot of peak current ( $\mathrm{Zn}$ ) against $X_{1}$ and $X_{3}$

c. Plot contour and surface response on condition $x_{2}$ and $x_{3}$ at stationary point

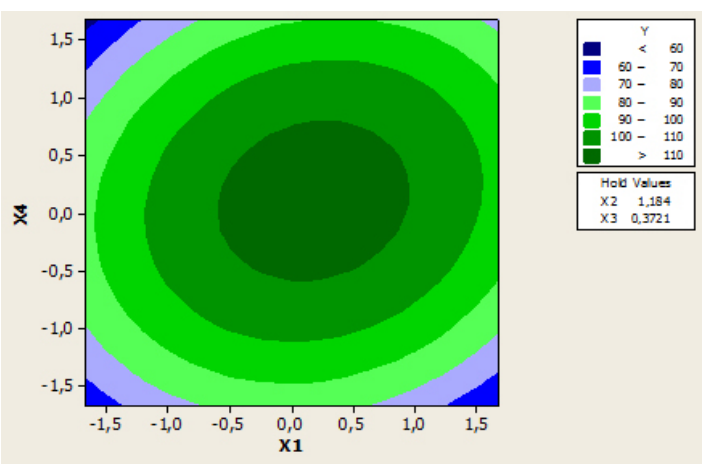

Contour plot of peak current (Zn) against $x_{1}$ and $x_{4}$

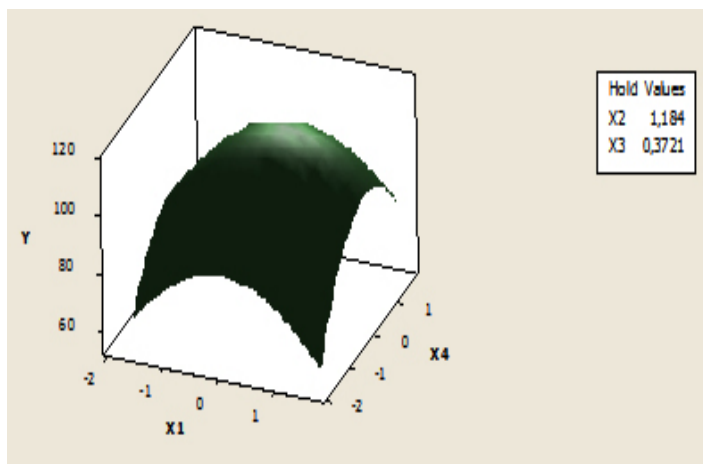

Surface plot of peak current ( $Z n)$ against $x_{1}$ and $x_{4}$ 
d. Plot contour and surface response on condition $x_{1}$ and $x_{4}$ at stationary point

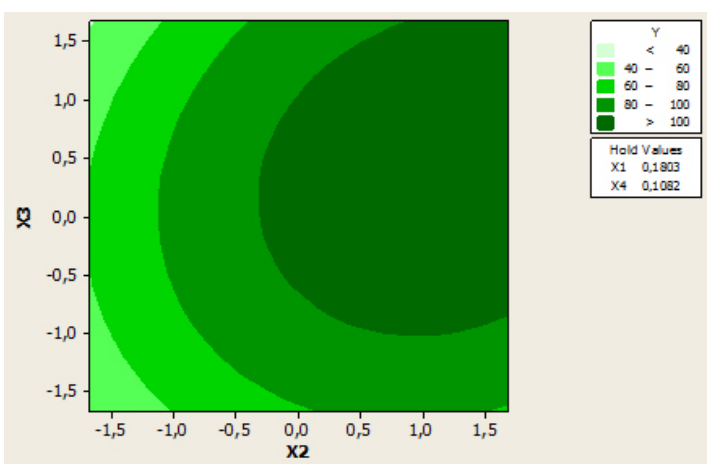

Contour plot of peak current $(\mathrm{Zn})$ against $x_{2}$ and $x_{3}$

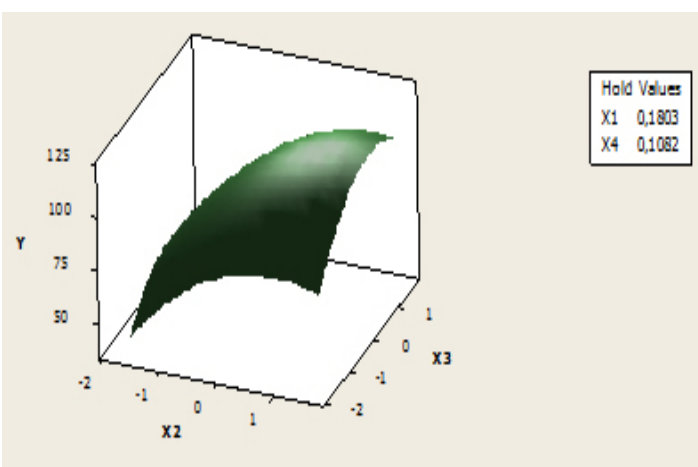

Surface plot of peak current $(\mathrm{Zn})$ against $x_{2}$ and $x_{3}$

e. Plot contour and surface response under conditions $x_{1}$ and $x_{3}$ at stationary point

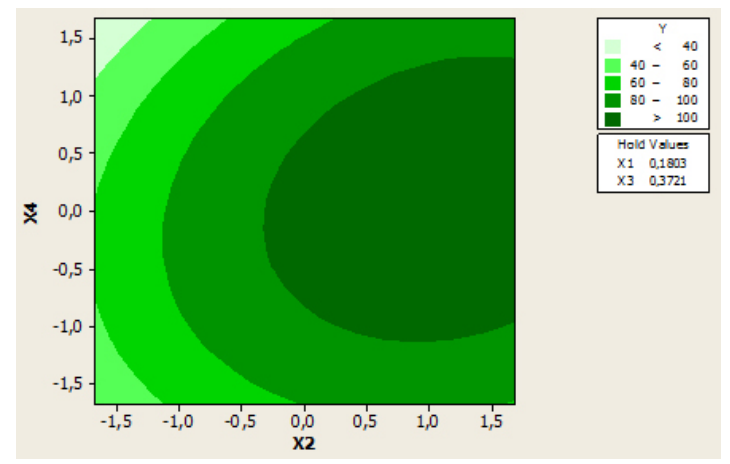

Contour plot of peak current $(\mathrm{Zn})$ terhadap $\mathrm{X}_{2}$ dan $\mathrm{X}_{4}$

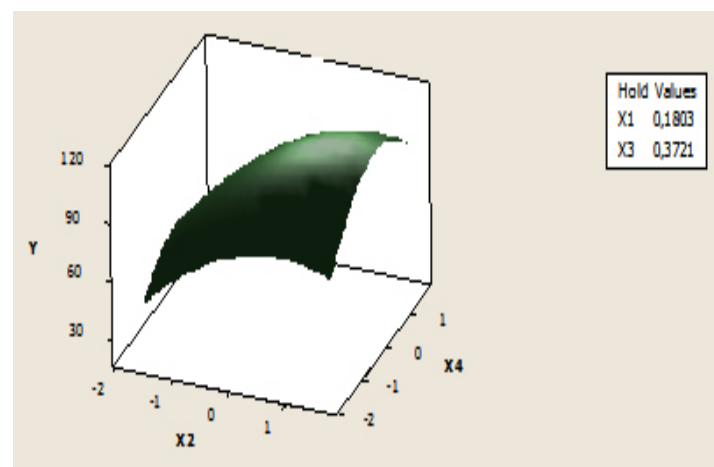

Surface Plot of peak current $(\mathrm{Zn})$ against $X_{2}$ and $X_{4}$

f. Plot contour and surface response under conditions $x_{1}$ and $x_{2}$ at stationary point

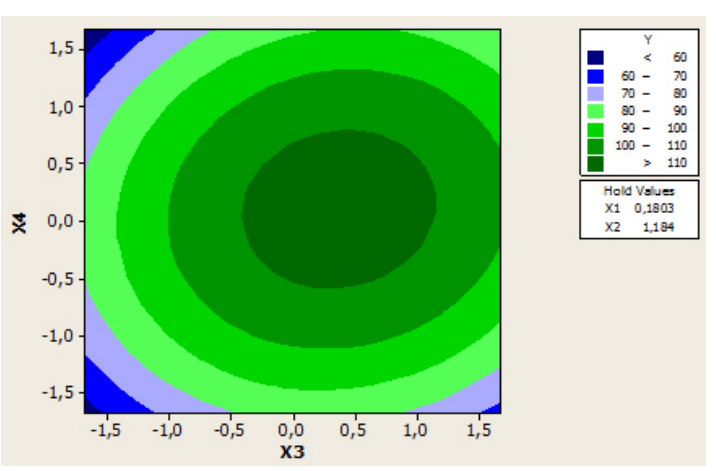

Contour Plot of peak current $(\mathrm{Zn})$ against $X_{3}$ and $X_{4}$

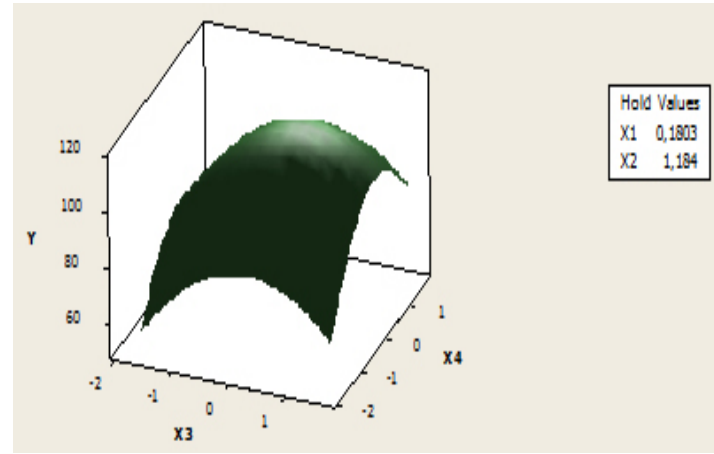

Surface plot of peak current (Zn) against $\mathrm{X}_{3}$ dan $\mathrm{X}_{4}$ 


$$
\begin{aligned}
b & =\left[\begin{array}{c}
0,2436 \\
14,2738 \\
2,9118 \\
-2,4124
\end{array}\right] \text { dan } \\
B & =\left[\begin{array}{cccc}
-7,96601 & 0,98313 & 0,09000 & 1,07375 \\
0,98313 & -6,67232 & 1,13750 & 1,53375 \\
0,09000 & 1,13750 & -7,79458 & 0,74562 \\
1,07375 & 1,53375 & 0,74562 & -9,99844
\end{array}\right]
\end{aligned}
$$

So obtained the stationary point as follows:

$$
x_{0}=-\frac{B^{-1} b}{2}=\left[\begin{array}{c}
0,18026 \\
1,18448 \\
0,37207 \\
0,10816
\end{array}\right]
$$

Thus, the response solution at the stationary point is obtained as follows:

$$
\hat{y}=\hat{\beta_{0}}+\frac{1}{2} x_{0}{ }^{\prime} b=105,833+8,88677=114,720
$$

Furthermore the stationary point can be returned to the real value, the conditions obtained that provide the optimal solution are as follows:

Where : calcon concentration $\left(x_{1}\right), \mathrm{pH}\left(\mathrm{x}_{2}\right)$, potential accumulation $\left(\mathrm{x}_{3}\right)$, and time accumulation $\left(\mathrm{x}_{4}\right)$

\section{Analysis of Response Surface Characteristics}

To get an idea of the surface characteristics of the response, we first calculate the eigen value $(\lambda)$ of the matrix $B$ and obtain

$\lambda=\left[\begin{array}{llll}-10,8112 & -8,8183 & -7,9457 & -4,8561\end{array}\right]$

Since the four eigen values are negative, the response surface shape is maximum. It can also be viewed from contour plots and surface response plots. By constructing two constants between the 4 factors observed at the stationary point, a contour plot and response surface can be constructed as shown in the figure below.

Based on data analysis with surface response method, it is concluded that peak current will reach maximum value at the time of calcon concentration $=0.7018 \mathrm{mM}, \mathrm{pH}=7.1845$, potential accumulation $-0.5628 \mathrm{~V}$ and time accumulatin $62.1632 \mathrm{~s}$. The maximum value of the peak current is $1143.720 \mathrm{nA}$.
Plot contour and surface response at stationary point (Figure 2)

By making a constant of two of the four factors used, it can be shown that the contour and the response surface are the maximum. In Figure 2, the contour plot will be presented and the surface of each possible pair of factors used by taking the condition of another factor is at a stationary point.

Based on Figure 2, it can be seen the range of values of each pair of variables that allegedly will give the maximum value. As described previously, that at the stationary point obtained an optimum response value of 114.720 . As an alternative to achieving the optimum response value, a combination of other values can be used as shown by the innermost circle of the contour plot. All pairs

Table 6: Comparison of methods of determination of $\mathrm{Zn}$ in vegetable and fruit samples

\begin{tabular}{lll}
\hline Sample & $\begin{array}{l}\text { Metode AdSV } \\
\text { (mg/L) }\end{array}$ & $\begin{array}{l}\text { Metode AAS } \\
\text { (mg/L) }\end{array}$ \\
\hline Broccoli & 2.712 & 1.238 \\
Cauliflower & 2.198 & 1.218 \\
Eggplant & 2.153 & 1.471 \\
Mustard & 4.598 & 1.216 \\
Apples & 2.176 & 1.270 \\
Banana kepok & 5.786 & 1.417 \\
Dragon fruit & 7.453 & 1.241 \\
Melon & 4.091 & 1.232 \\
\hline
\end{tabular}

Table 7: Determination of $\mathrm{Zn}$ in environmental samples by AdSV using calcon

\begin{tabular}{ll}
\hline Sample & Zn (mg/L) \\
\hline Broccoli & 2.785 \\
Cauliflower & 1.88 \\
Eggplant & 2.005 \\
Mustard & 4.876 \\
Apples & 2.105 \\
Banana kepok & 7.412 \\
Dragon fruit & 7.612 \\
Melon & 3.871 \\
Sea water & 0.062 \\
Tap water & 0.034 \\
Water from Maninjau & 0.193 \\
Water from river & 0.010 \\
\hline
\end{tabular}


of points that are in this deepest circle are expected to produce a maximum response value with the following details:

1. Each pair of points in the innermost circle of the plot between $x_{1}$ and $x_{2}$ will result in a predicted value of $>100$ response

2. Each pair of points in the innermost circle of the plot between $x_{1}$ and $x_{3}$ will produce an estimated value of $>110$ response

3. Each pair of points in the innermost circle of the plot between $x_{2}$ and $x_{3}$ will produce an estimated value of $>110$ response

4. Each pair of points in the innermost circle of the plot between $x_{1}$ and $x_{4}$ will result in a predicted value of $>100$ response

5. Each pair of points in the innermost circle of the plot between $x_{2}$ and $x_{4}$ will result in a predicted value of $>100$ response

6. Each pairs of points in the innermost circle of the plot between $x_{3}$ and $x_{4}$ will produce an estimated value of $>110$ response

It can be given the choice of alternatives to generate maximum response values, there is flexibility in determining the level of each factor that is thought to be capable of generating maximum response value.

\section{Application Method}

To evaluate the validation of the proposed method for the analysis of real samples, the proposed procedure is applied to various samples such as water samples (sea water, tap water, river and lake water), vegetables (cabbage, broccoli, mustard greens, eggplant) (Apple, dragon fruit, melon and banana kepok). The Zinc concentration in the sample can be seen in Table 6 . determined by the standard addition method using the recommended procedure under optimum conditions in the sample of vegetables and fruits

The results from Table 6 show that the AdSV method gives satisfactory results when compared to the atomic absorption spectrophotometer (AAS) method. Furthermore, determination of $\mathrm{Zn}$ metal in environmental samples in AdSV by using calcon, can be seen in Table 7.

\section{ACKNOWLEDMENT}

The authors are grateful to Ministry of Research and Higher Education for supporting this work Number : 01/UN.16.17/PP.Proter/LPPM/2017, April 7, 2017.

\section{CONCLUSION}

Based on data analysis with RSM, obtained optimum condition of the simultaneous determination zinc, calcon concentration: $0.70 \mathrm{mM}$, at $\mathrm{pH} 7.18$, potential accumulation $-0,56 \mathrm{~V}$ and time accumulation $62.16 \mathrm{sec}$. From the optimum condition obtained by value of RSD $2.5 \%$ with recovery $98.01 \%$, linear range $(0.2-105) \mu \mathrm{g} / \mathrm{L}$, and LOD $1.21 \mu \mathrm{g} / \mathrm{L}$. This RSM can be applied to the simultaneous determination of zinc in environmental samples (water: lakes, taps, sea, rivers, fruits: apples, dragon fruit, cantaloupe and banana kepok and vegetables: broccoli, cauliflower, mustard and eggplant) effective.

\section{REFERENCES}

1. Wang, S; Xu, H; Li, J. Chinese J. Anal. Chem. 2002, 30(8), 1005-1011.

2. Gupta, VK; Sethi, B; Sharma, RA; Agarwal, S; Bharti, A. J. Mol. Liq. 2013, 177, 114-118.

3. Krausa, M; Schorb, K. J. Electroanal. Chem. 1999, vol 1-2, 10-14.

4. Deswati; Suyani, H; Safni. Indones. J. Chem. 2012, 12(1), 20 -27.

5. Ensafi, A.A., Abbasi, S; Mansour, HR. Anal. Sci. 2001, 17, 609-612.

6. Zang, S; Huang, W. Anal. Sci. 2001, 17, 983-
985.

7. Deswati; Buhatika, C; Suyani, H; Emriadi; Loekman, U. Int. J. Res. Chem. Environ. 2014, 4(2), 143 -152.

8. Deswati; Munaf, E; Suyani, H; Loekman, U; Pardi, H. Res. J. Pharm, Biol and Chem. Sci. 2014, 5(4), 990-999.

9. Deswati; Amelia, L; Suyani, H; Zein, R; Jin, J. Rasayan. J. Chem. 2015, 8(3), 362-372.

10. Deswati; Suyani, H; Zein, R; Refilda; Sutopo, J. J. Chem, Pharm Res. 2015, 7(8), 942-947. 
11. Deswati; Suyani, H; Zein, R; Alif, A; Pardi, $H$. J. Chem, Pharm Res. 2015, 7(10), 833 -840.

12. Deswati; Pardi, H; Suyani, H; Zein, R and Edelw, T.W. Anal \& Bioanal. Electrochem. 2016, 8(7), 885 - 898.

13. Deswati; Pardi, H; Suyani, H and Zein, R. Oriental J.Chem. 2016, 32(6), 3071-3080.

14. Deswati; Suyani, H; Zein, R; Alif, A; Pardi, H. Rasayan J. Chem., 2017, 10(2), 549-557.

15. Jugade, R.M; Joshi, AP. Anal. Sci. 2006, 22, 571-574.

16. Proti, P. Introduction to modern Voltammetric and polarographic analysis techniques. Amel Electrochemistry Ed. IV, 2001.

17. Richard, JC; Martin, J; Milton, T. Trend in Anal. Chem. 2005, 24(3), 266 - 274.

18. Amini, MK; Kabiri, M. J. Iran. Chem. Soc. 2005, 2, 32-39.

19. Deswati; Suyani, H; Safni; Loekman, U; Pardi, H. Indones. J. Chem., 2013, 13(3), $236-241$.

20. Deswati; Munaf, E; Suyani, H; Zein, R; Pardi, H. Asian J. Chem. 2015, 27(11), 3978-3982.

21. Deswati; Suyani, H; Zein, R; Izzati Rahmi, HG. J. Chem. Pharm. Res. 2015, 7(8), 750 -757.

22. Deswati; Izzati Rahmi, HG; Suyani, H; Zein, R. J. Chem. Pharm. Res. 2015, 7(10), 862-870.

23. Deswati; Izzati Rahmi, HG; Suyani, H; Zein, R;. Alif, A. Rasayan. J. Chem. 2016, 9(1), 8-17.

24. Deswati; Izati Rahmi, HG; Suyani, H; Zein, R; .Alif, A. Oriental J. Chem. 2016, 32(3), 1493-
1502.

25. Paolicchi, I; Renedo, OD; Lomillo, MAL; Martinez, MAA. Anal. Chim. Acta. 2004, 511, $223-229$.

26. Morgan, E. Chemometrics: Experimental design , ACOL, Newyork, Wiley, 1991.

27. Jurado-Gonzales, JA; Galindo-Riano, MD; Garcia-Vargas, M. Anal Chim Acta. 2003, 487, 229-41

28. Izzati Rahmi, HG; Deswati; Suyani, H; Zein, R. Res. J. Pharm, Biol and Chem. Sci. 2016, 7(3), 673-682.

29. Dewi, AK; Sumarjaya, IW; Srinadi, IGAM. E-Jurnal Matematika. 2013, 2(2), 32-36.

30. Bezerra, MA; Santelli, RE; Oliveira, EP Villar, LS; Escaleira, LA. Talanta. 2008, 76, 965 977.

31. Yilmaz, S; Ozturk, B; Ozdemir,D; Eroglu, AE; Ertas, FN. Turk. J. Chem. 2013, 37, 316 $-324$.

32. Ensafi, A.A; Khayamian, T; Benvidi, A; Mirmomtaz, E. Anal. Chimica Acta. 2006, 561, 225-232.

33. Miller, J.C; Miller, J.N. Statistics for Analytical Chemistry. Ellis Horwood, New York, 1994.

34. Sulaeman, Suparto and Eviati. Technical guidelines for chemical analysis of soil, plants, water and fertilizers. Agency for Agricultural Research and Development, Ministry of Agriculture. 2005. 